\title{
Composition and chemical bonding of pulsed laser deposited carbon nitride thin films
}

\author{
E. Riedo, ${ }^{\text {a) }}$ F. Comin, and J. Chevrier ${ }^{\text {b) }}$ \\ ESRF, BP220 F-38043 Grenoble Cedex France
}

\author{
A. M. Bonnot \\ LEPES CNRS Grenoble, France
}

(Received 23 November 1999; accepted for publication 13 July 2000)

\begin{abstract}
We studied composition, structure, and growth parameters of amorphous diamond-like carbon (DLC) and carbon nitride $\left(\mathrm{CN}_{x}\right)$ films deposited by pulsed laser deposition in vacuum and in nitrogen atmosphere. The composition $(0 \leqslant \mathrm{~N} / \mathrm{C} \leqslant 0.4)$, the structural and the electronic properties of the deposited carbon and carbon nitride films were investigated for different laser fluences $(1-12$ $\mathrm{J} / \mathrm{cm}^{2}$ ). Electron energy loss spectroscopy, $\mathrm{x}$-ray photoelectron spectroscopy, and micro-Raman spectroscopy indicated an increase in $s p^{3}$-bonded carbon sites in the DLC films and an increase in $\mathrm{N}-s p^{3} \mathrm{C}$ bonded sites in the $\mathrm{CN}_{x}$ films with increasing deposition laser fluence. Raman spectroscopy also showed the presence of a small amount of $\mathrm{C} \equiv \mathrm{N}$ bonds in the $\mathrm{CN}_{x}$ films . Furthermore, we observed that keeping the nitrogen pressure constant ( $P=100 \mathrm{mTorr}$ ) the increase in the deposition laser fluence is reflected by an increase in the nitrogen content in the films. All the results have been discussed in the framework of different theoretical models. (C) 2000 American Institute of Physics. [S0021-8979(00)08120-2]
\end{abstract}

\section{INTRODUCTION}

Carbon can exist in an amorphous state that can display a wide range of properties depending on the short-range order of the structure, such as bonding state of carbon atoms, the proportion of different bonding states, and composition. Amorphous carbon films with diamond like properties have very attractive properties such as extreme hardness, infrared transparency, chemical inertness, and excellent tribological, corrosion, and adhesion properties. ${ }^{1}$ Owing to their unique properties diamond-like carbon (DLC) films have found a wide range of technological applications: as hard coatings for magnetic disk drives, as antireflection coatings for IR windows, and as cold cathodes for field emission displays. ${ }^{2,3}$ In order to improve DLC properties, many attempts have been carried out by adding dopants such as silicon, boron, and nitrogen. ${ }^{4-6}$

A tendency towards carbon nitride $\left(\mathrm{CN}_{x}\right)$ films in carbon overcoats is now taking place due to the improved wear durability, the lower friction coefficient, the higher elasticity, and compatibility with existing lubricants. ${ }^{7}$

DLC and $\mathrm{CN}_{x}$ films can be grown with different methods such as sputter deposition, cathodic arc, direct ion beam deposition, ${ }^{8}$ chemical vapor deposition, ${ }^{9}$ plasma enhanced chemical vapor deposition, ${ }^{4}$ and pulsed laser deposition (PLD). ${ }^{10}$ This last method is particularly attractive because it can be easily carried out even on nonconductive substrates and at low substrate temperature during film growth. ${ }^{11}$ There are still several open questions regarding how the growth

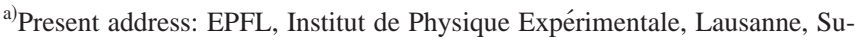
isse; Also at: INFM-Dipartmento di Scienze dei Materiali, Università di Milano; electronic mail: riedo@dpmail.epfl.ch

b) Also at: LEPES CNRS Grenoble.
}

conditions influence the resulting structure in DLC and $\mathrm{CN}_{x}$ films. ${ }^{12}$ Carbon atoms in nonhydrogenated $a$-C films form chemical bonds among them by hybridization of their outmost $\sigma$ and $\pi$ orbitals in tetrahedral ( $s p^{3}$ hybridization), dihedral ( $s p^{2}$ hybridization), and less extendedly linear ( $s p^{1}$ hybridization) spatial configurations. These configurations correspond to different coordination numbers and also the chemical bonds are different. $\sigma$ bonds are more energetic and stiffer than the $\pi$ bonds and consequently they are responsible for the mechanical properties of the $\mathrm{C}$ films such as hardness. The improvement of the quality of the films (e.g., the hardness) is strictly correlated with the increase in the $s p^{3}$ (only $\sigma$ bonds) concentration in the film. ${ }^{1}$ An important parameter characterizing the films prepared under different deposition conditions is, hence, the $s p^{3} / s p^{2}$ ratio.

In our experiment amorphous DLC and carbon nitride thin films were deposited by laser ablation of graphite under vacuum conditions and nitrogen atmosphere. Since nitrogen is a weak dopant for carbon, techniques like core level analysis are required to establish the chemical bonds of nitrogen with carbon. In this article we will present our results concerning the use of x-ray photoelectron spectroscopy (XPS), electron energy loss spectroscopy (EELS), and micro-Raman spectroscopy to investigate how the laser fluence changes the composition, the structural, and the electronic properties of $\mathrm{CN}_{x}$ films. Some of our results concerning the DLC films are already well known in the literature; nevertheless they are reported because they can help to better draw the conclusions on the $\mathrm{CN}_{x}$ films.

\section{EXPERIMENTAL METHODS}

DLC and $\mathrm{CN}_{x}$ films were deposited in a pulsed laser deposition system consisting of an ultrahigh vacuum (UHV) 
chamber with a base pressure of $1 \times 10^{-9}$ Torr and a $Q$-switched Nd:YAG laser with a wavelength of $532 \mathrm{~nm}$, a pulse duration of $20 \mathrm{~ns}$ and a frequency of $10 \mathrm{~Hz}$. The distance between the target and the substrate was $3 \mathrm{~cm}$. The laser fluence ranged from 1 to $35 \mathrm{~J} / \mathrm{cm}^{2}$ for the DLC films and from 1 to $12 \mathrm{~J} / \mathrm{cm}^{2}$ for the $\mathrm{CN}$ films. During the growth of $\mathrm{CN}_{x}$ films we used a nitrogen pressure of 100 mTorr. Silicon wafers, cleaned with acetone, were used as substrates.

After the deposition process, the samples were immediately loaded into an UHV system where carbon and nitrogen bonding configuration, chemical composition, and electronic structure were determined by XPS core level and EELS low energy spectra. These measurements were performed at the base pressure of $1 \times 10^{-10}$ Torr. Core levels were measured using an $\mathrm{Al} K_{\alpha} 1486 \mathrm{eV}$ x-ray source. Charging effects were not observed on the samples during measurements. The resulting experimental resolution, including the width of the $\mathrm{x}$-ray line and the energy resolution of the analyzer, was about $1.1 \mathrm{eV}$. The Si $2 p$ core level of an uncovered part of the silicon substrate was used to calibrate the scale of the binding energies, whereas to calculate the chemical composition at the surface we used standard sensitivity values. EELS measurements were performed using an EG5 VSW Scientific Instruments electron gun. We studied energy losses in the range from zero (at the primary electron energy) to $50 \mathrm{eV}$. The energy resolution, as deduced from the width of the primary peak, was $2 \mathrm{eV}$. For both XPS and EELS measurements we utilized a hemispherical analyzer. A DEK TEK profilometer was used to measure the thickness of the samples. The average thickness of the deposited films is 100 $\mathrm{nm}$. The growth rate changes significantly with the laser fluence varying from $200 \AA / \mathrm{min}$ for $I_{L}=35 \mathrm{~J} / \mathrm{cm}^{2}$ to $6 \AA / \mathrm{min}$ for $I_{L}=1 \mathrm{~J} / \mathrm{cm}^{2}$. The $\mathrm{O} 1 \mathrm{~s} / \mathrm{C} 1 \mathrm{~s}$ intensity ratio, evaluated by taking into account the $\mathrm{O} 1 s$ and $\mathrm{C} 1 s$ sensitivity factors, is 0.03 for all the $\mathrm{C}$ samples and about 0.1 for the $\mathrm{CN}_{x}$ samples.

Micro-Raman spectroscopy provided additional information on the film structure. These measurements were made using a LabRam Infinity Dilor apparatus probing an area of the order of a few micrometers and using either the $633 \mathrm{~nm}$ $\mathrm{He}-\mathrm{Ne}$ laser radiation or the $458 \mathrm{~nm}$ Ar laser radiation.

\section{RESULTS AND DISCUSSION}

\section{A. Core level x-ray photoelectron spectroscopy}

The N/C ratio of the deposited $\mathrm{CN}$ thin films was measured by the $\mathrm{C} 1 s$ and $\mathrm{N} 1 s$ core level spectra taking into account the $\mathrm{C} 1 s$ and $\mathrm{N} 1 s$ sensitivity factors. We found out that the $\mathrm{N} / \mathrm{C}$ ratio increases with the laser fluence in the range $5-12 \mathrm{~J} / \mathrm{cm}^{2}$. We obtained $\mathrm{N} / \mathrm{C}=0.3$ for a laser fluence of $5 \mathrm{~J} / \mathrm{cm}^{2}$ and $\mathrm{N} / \mathrm{C}=0.40$ for $12 \mathrm{~J} / \mathrm{cm}^{2}$. This result is in agreement with previous works carried out with laser fluences in the range $3-12 \mathrm{~J} / \mathrm{cm}^{2},{ }^{13,14}$ however other authors ${ }^{15}$ have shown a decrease in the $\mathrm{N} / \mathrm{C}$ ratio for laser fluences increasing from 0.8 to $2 \mathrm{~J} / \mathrm{cm}^{2}$. Figure 1 shows the XPS C $1 \mathrm{~s}$ spectra of three $\mathrm{CN}_{x}$ films with different nitrogen content. The $\mathrm{C} 1 s$ peak broadens and becomes more asymmetric with increasing nitrogen concentration: the full widths at half maximum (FWHM) are equal to $1.8,3.2$, and $3.8 \mathrm{eV}$ for the

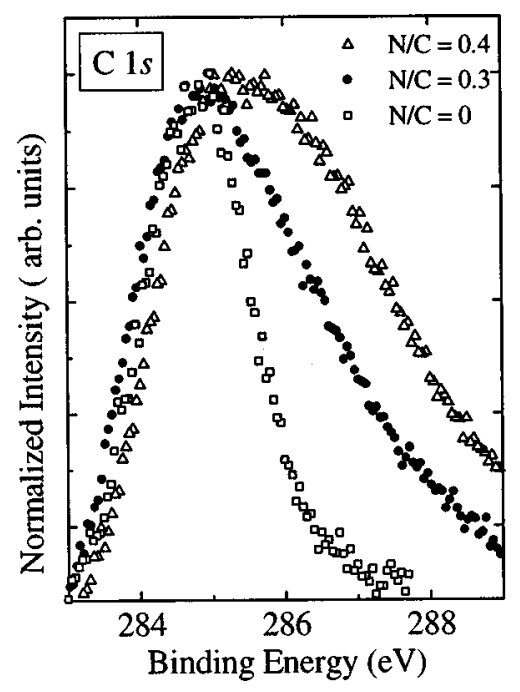

FIG. 1. C $1 s$ XPS spectra of three different $\mathrm{CN}_{x}$ films with $\mathrm{N} / \mathrm{C}=0,0.3$, and 0.4 .

films with $\mathrm{N} / \mathrm{C}=0,0.3$, and 0.4 , respectively. These effects are a clear indication that nitrogen atoms are involved in chemical bonds with carbon in three possible distinct chemical states: $\mathrm{C}-\mathrm{N}, \mathrm{C}=\mathrm{N}, \mathrm{C} \equiv \mathrm{N}$ bonds. An image of the possible chemical bonds between nitrogen and carbon in the films can be inferred from the deconvolution of the individual $\mathrm{C} 1 s$ and $\mathrm{N} 1 s$ lines into Gaussian line shapes. The interpretation of the respective contributions, however, diverges somewhat between different authors. Ronning et al. ${ }^{16}$ have presented a review on the different explanation of the contributions to the $\mathrm{N} 1 s$ and $\mathrm{C} 1 s$ core level lines. A common observation in almost all recent XPS works on $\mathrm{CN}_{x}$ films ${ }^{17-21}$ is that the $\mathrm{N} 1 s$ core level can be deconvoluted in two peaks located around binding energies of 398 and 401 $\mathrm{eV}$, a third peak at about $402 \mathrm{eV}$ related to $\mathrm{N}-\mathrm{O}$ bonds can also be present. The deconvolution of the $\mathrm{C} 1 s$ line seems to be more controversial for different reasons. First, this line appears sometimes featureless. ${ }^{19}$ Second, considerable variations in the $\mathrm{C} 1 \mathrm{~s}$ binding energy are found in different works, and finally some authors claim that there is no evidence for a significant difference in the $\mathrm{C} 1 s$ positions between graphite and diamond. ${ }^{21}$

We have normalized all the core level spectra to their own areas, in order to compare quantitatively the spectra of samples with a different content of nitrogen. The best Gaussian fits to the $\mathrm{N} 1 s$ core level lines resulted in three peaks as shown in Figs. 2(a) and 2(b) for the $\mathrm{CN}_{x}$ films with $\mathrm{N} / \mathrm{C}=0.3$ and 0.4 , respectively. These peaks are at about $399.7 \mathrm{eV}$ (N1), $401.2 \mathrm{eV}$ (N2), and $402.6 \mathrm{eV}$ (N3). The assignment of peaks N1 and N2 is still under debate, even if it is now generally agreed that the peak N1 is assigned to nitrogen bonded to $s p^{2}$-hybridized carbon, while peak N2 can be assigned to nitrogen bonded to $s p^{2}$-coordinated carbon. ${ }^{17,19,20-23}$ This interpretation is also supported by $a b$ initio binding energies calculations. ${ }^{23}$ However, this interpretation is in contrast with the studies of other authors. ${ }^{13,16} \mathrm{We}$ relate peak $\mathrm{N} 1$ to $\mathrm{C}-\mathrm{N}$ bonds, peak $\mathrm{N} 2$ to $\mathrm{C}=\mathrm{N}$ bonds and peak $\mathrm{N} 3$ to $\mathrm{N}-\mathrm{O}$ bonds. The results of the fit are reported in Table I. These results show that there is a higher concentra- 

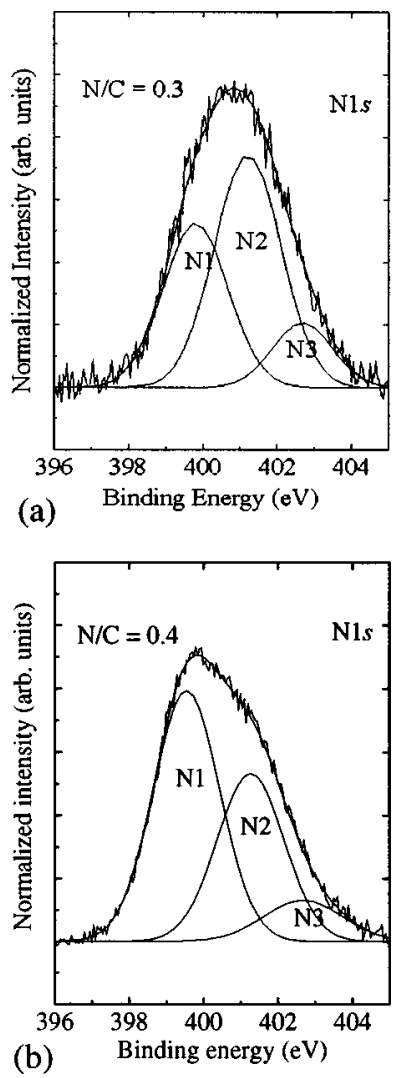

FIG. 2. Deconvoluted N $1 s$ spectra for $\mathrm{CN}_{x}$ samples with (a) N/C=0.3 and (b) $\mathrm{N} / \mathrm{C}=0.4$.

tion of $\mathrm{C}=\mathrm{N}$ bonds corresponding to $\mathrm{N}-s p^{2} \mathrm{C}$ bonded sites in the sample with less content of nitrogen $(\mathrm{N} / \mathrm{C}=0.3)$ and grown with lower laser fluence. The ratio A1/A2 between the areas related to peak $\mathrm{N} 1(\mathrm{C}-\mathrm{N})$ and $\mathrm{N} 2(\mathrm{C}=\mathrm{N})$ results to be 0.69 for the sample with $\mathrm{N} / \mathrm{C}=0.3$ and 1.44 for the sample with $\mathrm{N} / \mathrm{C}=0.4$.

In the fit of the $\mathrm{C} 1 s$ peaks we have imposed a deconvolution in four peaks $\mathrm{C} 1, \mathrm{C} 2, \mathrm{C} 3$, and $\mathrm{C} 4$ which were attributed to $\mathrm{C}-\mathrm{C}(\mathrm{C} 3), \mathrm{C}=\mathrm{N}(\mathrm{C} 2), \mathrm{C}-\mathrm{N}(\mathrm{C} 1)$, and $\mathrm{C}-\mathrm{O}(\mathrm{C} 4)$. The $\mathrm{C} 3$ peak attributed to $\mathrm{C}-\mathrm{C}$ bonds is situated at an intermediate position between the two $\mathrm{C} 1 s$ peaks relative to $\mathrm{C}-\mathrm{C} s p^{2}$ bonds in graphite and to $\mathrm{C}-\mathrm{C} s p^{3}$ bonds in diamond. ${ }^{24}$ This interpretation is in agreement with the assignment of Marton and co-workers ${ }^{17}$ and of other authors. ${ }^{7,25,26}$ We have fixed the ratio between the areas of

TABLE I. Binding energies and areas of the peaks resulting from the deconvolution of the N $1 s$ spectra in Figs. 2(a) and 2(b).

\begin{tabular}{lccc}
\hline \hline \multicolumn{1}{c}{$\mathrm{N} 1 s$} & $\mathrm{~N} / \mathrm{C}$ & $X=0.3$ & $X=0.4$ \\
\hline $\mathrm{C}-\mathrm{N}$ & $\mathrm{N} 1$ & 399.80 & 399.5 \\
or C $\equiv \mathrm{N}$ & & & \\
$\mathrm{C}=\mathrm{N}$ & $\mathrm{N} 2$ & 401.21 & 401.27 \\
$\mathrm{~N}-\mathrm{O}$ & $\mathrm{N} 3$ & 402.67 & 402.68 \\
& Area 1 & 0.361 & 0.534 \\
& Area 2 & 0.515 & 0.370 \\
& Area 3 & 0.128 & 0.102 \\
& Area 1/Area 2 & 0.69 & 1.44 \\
& $\chi^{2}$ & $3 \times 10^{-5}$ & $9 \times 10^{-5}$ \\
\hline \hline
\end{tabular}

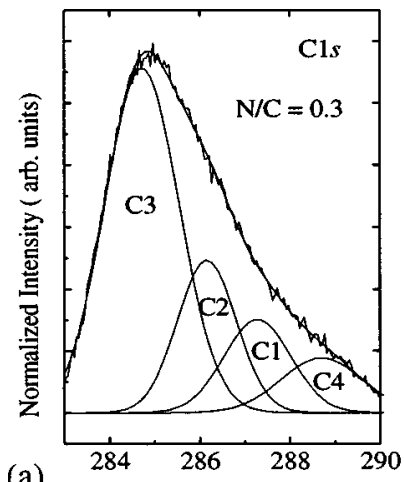

(a)

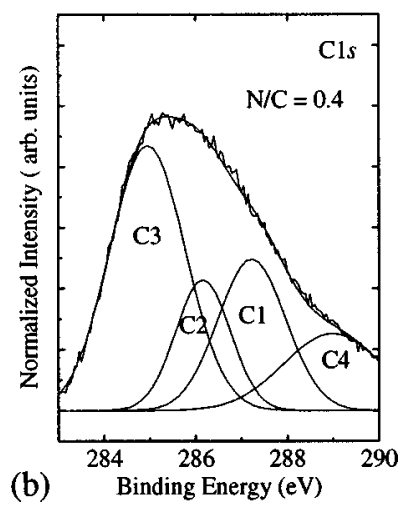

FIG. 3. Deconvoluted C $1 s$ spectra for $\mathrm{CN}_{x}$ samples with (a) N/C=0.3 and (b) $\mathrm{N} / \mathrm{C}=0.4$.

the peaks $\mathrm{C} 1$ and $\mathrm{C} 2$ equal to 0.69 for the sample with N/C $=0.3$ and to 1.44 for the sample with $\mathrm{N} / \mathrm{C}=0.4$. The resulting deconvolutions of the $\mathrm{C} 1 \mathrm{~s}$ spectra, shown in Figs. 3(a) and 3(b), exhibit peaks at about $284.8 \mathrm{eV}$ (C3), $286.1 \mathrm{eV}$ (C2), $287.2 \mathrm{eV}(\mathrm{C} 1)$, and $288.8 \mathrm{eV}$ (C4). The results of these fits are summarized in Table II. We would like to underline that our interpretation of the components of the $\mathrm{N} 1 s$ and $\mathrm{C}$ $1 s$ core level lines is coherent with the values of the binding energies $(\mathrm{BE})$ of reference organic polymers containing nitrogen. Pyridine $\left(\mathrm{C}=\mathrm{N}, s p^{2}\right.$ hybridization) has a $\mathrm{C} 1 s \mathrm{BE}$ at $285.5 \mathrm{eV}^{17,25-27}$ and a N $1 s$ BE at $400.6 \mathrm{eV} .{ }^{25-27}$ Urotropine or HMTA (C-N, $s p^{3}$ hybridization), exhibits a $\mathrm{C} 1 s \mathrm{BE}$ at $286.9 \mathrm{eV} \quad[287.3 \mathrm{eV}$ for hexamethylenetetramine (HMTA) $]^{17,28-30}$ and a N $1 s$ BE at $399.4 \mathrm{eV} .^{17}$

TABLE II. Binding energies and areas of the peaks resulting from the deconvolution of the C $1 s$ spectra in Figs. 3(a) and 3(b).

\begin{tabular}{lccc}
\hline \hline \multicolumn{1}{c}{$\mathrm{C} 1 s$} & $\mathrm{~N} / \mathrm{C}$ & $X=0.3$ & $X=0.4$ \\
\hline $\mathrm{C}-\mathrm{C}$ & $\mathrm{C} 3$ & 284.72 & 284.95 \\
$\mathrm{C}=\mathrm{N}$ & $\mathrm{C} 2$ & 286.16 & 286.16 \\
$\mathrm{C}-\mathrm{N}$ & $\mathrm{C} 1$ & 287.28 & 287.22 \\
or C $\equiv \mathrm{N}$ & & & \\
$\mathrm{C}-\mathrm{O}$ & $\mathrm{C} 4$ & 288.7 & 288.99 \\
& Area 3 & 0.575 & 0.449 \\
& Area 2 & 0.200 & 0.16 \\
& Area 1 & 0.14 & 0.23 \\
& Area 4 & 0.10 & 0.16 \\
& Area 1/Area 2 & 0.69 & 1.44 \\
& $\chi^{2}$ & $2 \times 10^{-5}$ & $3 \times 10^{-5}$ \\
\hline \hline
\end{tabular}


The deconvoluted peaks from the $\mathrm{C} 1 s$ spectra at $\approx 287$ $\mathrm{eV}(\mathrm{C} 1)$ and from the $\mathrm{N} 1 s$ spectra at $\approx 399 \mathrm{eV}(\mathrm{N} 1)$ could also be assigned to $\mathrm{C} \equiv \mathrm{N}$ bonds ${ }^{16,18,26,31}$ but the binding energy of the peak $\mathrm{C} 1$ in both the samples [Figs. 3(a) and 3(b)] is at $287.2 \mathrm{eV}$ which is much closer to the values 286.8 and $287.3 \mathrm{eV}$ of materials with $s p^{3}$ configuration with respect to the value $286.4 \mathrm{eV}$ of polyacrylonitrile ( $\mathrm{C} \equiv \mathrm{N}$ bonds). A confirmation of the fact that the peaks $\mathrm{C} 1$ and $\mathrm{N} 1$ in both the $\mathrm{CN}_{x}$ samples are related to $\mathrm{C}-\mathrm{N}$ bonds instead of $\mathrm{C} \equiv \mathrm{N}$ bonds comes also from the Raman spectra in Fig. 6. These spectra, in fact, show that there is only a weak signal from $\mathrm{C} \equiv \mathrm{N}$ bonds in the films and that this signal is the same in both the studied $\mathrm{CN}_{x}$ films. In any case we have to underline that no investigation about the IR/Raman sensitivity factors for the different bond configurations in $\mathrm{CN}$ films have been published to our knowledge.

The reliability of our fitting procedure was checked along the following lines. The Gaussian line width of all the components is determined by the instrumental broadening that is $1.1 \mathrm{eV}$ and further broadening can be expected due to chemical disorder and phonon broadening. In our experiment the FWHM of the deconvoluted peaks both in the C $1 s$ and $\mathrm{N} 1 s$ spectra result to be about $1.6 \mathrm{eV}$ for the peak $\mathrm{C}-\mathrm{C}, 1.2$ $\mathrm{eV}$ for the peak $\mathrm{C}=\mathrm{N}, 1.4 \mathrm{eV}$ for the peak $\mathrm{C}-\mathrm{N}$, and about $2 \mathrm{eV}$ for the peak $\mathrm{C}-\mathrm{O}$ and $\mathrm{N}-\mathrm{O}$, these values are in good agreement with previous reports. ${ }^{25,26}$

The position of the individual components should not vary from film to film, and in this experiment we found that the binding energies of the individual components are the same in each film within $0.3 \mathrm{eV}$. Furthermore, it is worth noting that the sum of the areas of the peaks $\mathrm{C} 1$ and $\mathrm{C} 2$ is an aspect about 0.3 and 0.4 for the films with $\mathrm{N} / \mathrm{C}=0.3$ and 0.4 , respectively, whereas the areas related to the bonds $\mathrm{C}-\mathrm{O}$ are about 0.1 in all the spectra, coherently with the ratio $\mathrm{O} 1 s / \mathrm{C}$ $1 s$.

The analysis of the spectra in Figs. 2 and 3(a) and 3(b) shows that the percentage of $\mathrm{C}-\mathrm{N}$ bonds on the total amount of bonds between $\mathrm{C}$ and $\mathrm{N}$ increases from $36 \%$ to $53 \%$ with growing the $\mathrm{N} / \mathrm{C}$ ratio from 0.3 to 0.4 . Different authors found a similar trend ${ }^{19,22,23,25,26}$ and Sjöström et al. ${ }^{20}$ proposed a model to explain this behavior, supported by theoretical calculations. They suggested that when a small amount of nitrogen is incorporated in a hexagonal graphitic structure, the $\mathrm{N}$ atoms take substitutional positions in the graphite layers without changing the shape or the properties of the basal planes. For high concentrations there must be more than one $\mathrm{N}$ atom in some graphitic rings and this high local concentration of $\mathrm{N}$ can promote the formation of pentagons and facilitate the cross linking between the planes through $s p^{3}$-coordinated carbon atoms. Even if our $\mathrm{C}$ samples are rich of $s p^{3}$ hybridization, they still have about $50 \%$ of $s p^{2}$ hybridization and these graphitic domains can undergo the above-mentioned evolution to a three dimensional structure with the $\mathrm{N}$ content increase. Another recent theoretical work ${ }^{32}$ shows that the ratio $s p^{3} / s p^{2}$ grows with the nitrogen concentration. On the other hand, different authors $^{16,21}$ report opposite trends regarding the relation between $\mathrm{N}$ content and the percentage of $\mathrm{N}-s p^{3} \mathrm{C}$ bonded sites in the films. They studied ta-C samples with a starting per-

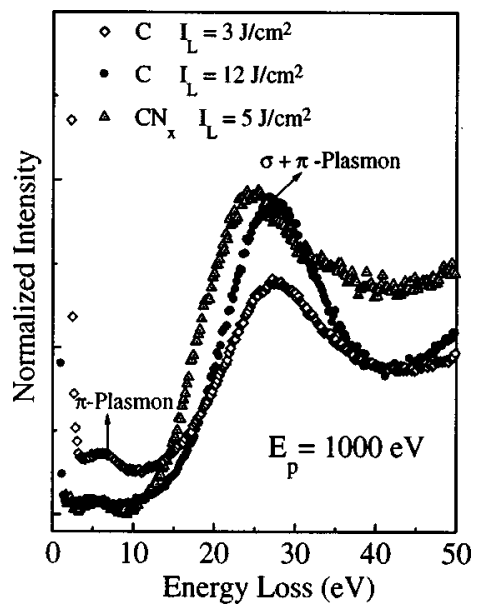

FIG. 4. EELS spectra of C films grown with laser fluences of 12 and $3 \mathrm{~J} / \mathrm{cm}^{2}$ and $\mathrm{CN}_{x}$ films grown with laser fluence of $5 \mathrm{~J} / \mathrm{cm}^{2}$.

centage of $s p^{3} \mathrm{C}-\mathrm{C}$ bonds of $70 \%-90 \%$ and they observed that the augmentation of the content of $\mathrm{N}$ corresponds to a partially transformation of the $s p^{3}-\mathrm{CN}$ bonded matrix into a polymeric configuration containing $\mathrm{C}=\mathrm{N}$ bonds.

From the XPS analysis some authors ${ }^{33}$ involved in the growth of $\mathrm{CN}$ films by PLD in nitrogen atmosphere claim that in their $\mathrm{CN}$ films there are only $\mathrm{N}-s p$ and $\mathrm{N}-s p^{2} \mathrm{C}$ bonded sites but this result is in contrast with different experimental works. ${ }^{13-15}$ In particular De Giorgi et al. ${ }^{13}$ reported that in their $\mathrm{CN}$ samples deposited by PLD, there is an increase in $\mathrm{N}-s p^{3} \mathrm{C}$ bonded sites with increasing the N/C ratio, in agreement with our measurements. Finally, it is important to consider the energy of the $\mathrm{C}$ ions as suggested by some authors. ${ }^{34,35}$ In agreement with their hypothesis in our experiment the films grown with higher laser fluence that means higher $\mathrm{C}$ ions energy ${ }^{10}$ are richer in $\mathrm{N}-s p^{3} \mathrm{C}$ bonded sites. Other studies on the growth of $\mathrm{CN}_{x}$ films by pulsed laser deposition show that the film quality increases with the laser fluence. ${ }^{13,14}$

\section{B. Electron energy loss spectroscopy}

In Fig. 4 we show the EELS of one $\mathrm{CN}_{x}$ film grown with laser fluence of $I_{L}=5 \mathrm{~J} / \mathrm{cm}^{2}(\mathrm{~N} / \mathrm{C}=0.3)$ and two $\mathrm{C}$ films grown with laser fluences of $I_{L}=3$ and $12 \mathrm{~J} / \mathrm{cm}^{2}$. The first peak at about $6 \mathrm{eV}$ called $\pi$-plasmon peak is related to the collective oscillations of the $\pi$ valence electrons and it is not present in a pure $s p^{3}$ configuration whereas it is present at $6.6 \mathrm{eV}$ in the graphite. ${ }^{36-38}$ The second peak at about $28 \mathrm{eV}$ is related to the $\sigma+\pi$ valence electrons. ${ }^{36-38}$ This peak is located at about $27 \mathrm{eV}$ in graphite and at $33 \mathrm{eV}$ in diamond. $^{36-38}$ Following a well established interpretation $^{19,36,37,39}$ the rise in Fig. 4 of the $\pi$-plasmon peak means an increase in the percentage of the $s p^{2}$ or $s p$ sites. The increase in $s p^{2} \mathrm{C}$ sites with decreasing the laser fluence in the DLC films is in agreement with other experimental works and with the subplantation model, ${ }^{35,39}$ bearing in mind that the laser fluence grows almost linearly with the energy of the carbon ions. ${ }^{10}$ The $\sigma+\pi$ plasmon peak is predicted by the quasifree electron model to $\mathrm{be}^{36-38}$ 


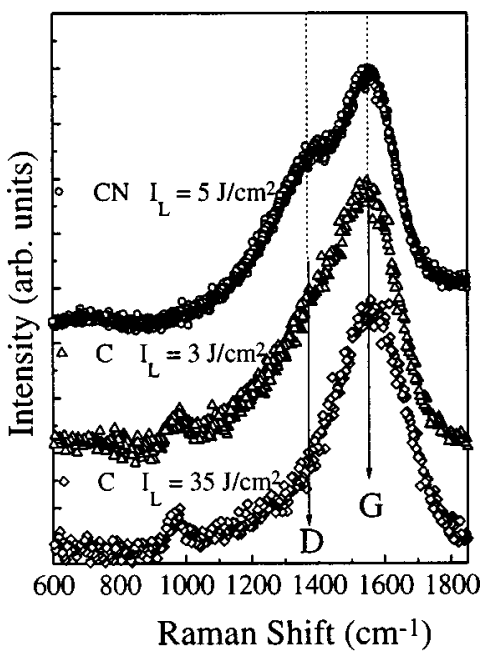

FIG. 5. Raman spectra of $\mathrm{C}$ films grown with laser fluences of 35 and 3 $\mathrm{J} / \mathrm{cm}^{2}$ and $\mathrm{CN}_{x}$ films grown with laser fluence of $5 \mathrm{~J} / \mathrm{cm}^{2}$ (from the bottom to the top, respectively).

$$
\omega_{p}=\left[\frac{4 \pi n_{e} e^{2}}{m^{*}}\right]^{1 / 2},
$$

where $n_{e}$ is the valence electron density of the material and $m^{*}$ and $e$ are the electronic effective mass and charge. From the spectra in Fig. 4 and using Eq. (1), it is possible to evaluate, approximately, the mass density of the different films. It was found that the density of the $\mathrm{CN}$ films and of the $\mathrm{C}$ films grown with low and high laser fluence are respectively: $\sim 1.96, \sim 2.37$, and $\sim 2.45 \mathrm{~g} / \mathrm{cm}^{3}$. The density calculated for the $\mathrm{CN}_{x}$ films is overestimated because the number of quasifree electrons in the $\mathrm{CN}_{x}$ films is five instead of four as in carbon. This means a strong decrease in the mass density of the $\mathrm{CN}$ films in comparison with the $\mathrm{C}$ films, in agreement with previous works ${ }^{16,21}$ and with the cluster assembled structure of these $\mathrm{CN}$ films observed with an atomic force microscopy. ${ }^{40}$

\section{Micro-Raman spectroscopy}

The Raman spectra were collected using two different wavelengths 458 and $632 \mathrm{~nm}$. All the required spectra result to be broader and less intense for $\lambda=632 \mathrm{~nm}$, and similar features are observed for $\lambda=458$ and $632 \mathrm{~nm}$. For this reason we do not show the spectra acquired with $\lambda=632 \mathrm{~nm}$, not providing more information on the structure and on the order of films than the spectra acquired with $\lambda=458 \mathrm{~nm}$. Figure 5 shows the Raman spectra of one $\mathrm{CN}_{x}$ film and two $\mathrm{C}$ films grown with different laser fluences: 3 and $35 \mathrm{~J} / \mathrm{cm}^{2}$. The Raman spectrum of the $\mathrm{C}$ film grown with high laser fluence $\left(I_{L}=35 \mathrm{~J} / \mathrm{cm}^{2}\right)$ exhibits an asymmetric broad single peak. The $\mathrm{C}$ films grown with lower laser fluence and the $\mathrm{CN}_{x}$ films show a second shoulder at lower wave numbers $\left(\sim 1360 \mathrm{~cm}^{-1}\right)$. This second peak increases in intensity in the $\mathrm{C}$ films by decreasing the deposition laser fluence. The peak located at a wave number of $1550 \mathrm{~cm}^{-1}$ (the so-called $G$ peak, $G$ for graphite) corresponds to the symmetric $E_{2 g}$ vibrational mode in graphite-like materials, whereas the $D$ band ( $D$ for disorder) at about $1360 \mathrm{~cm}^{-1}$ arises from the

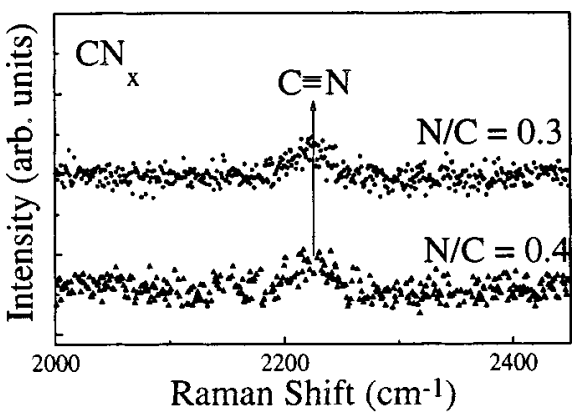

FIG. 6. Raman spectra of different $\mathrm{CN}_{x}$ films, shifted on the $y$ axis.

limitations in the graphite domain size, induced by grain boundaries or imperfections, such as substitutional $\mathrm{N}$ atoms, $s p^{3}$ carbon, or other impurities. ${ }^{41}$ Thus, the intensity of the $D$ band is quite sensitive to the size of crystalline microdomains. Furthermore, the width of the peaks also gives important information about the crystalline nature of the film. Amorphous materials give rise to broad diffuse peaks, whereas crystalline materials give rise to well-defined sharp peaks. All this remains true until the size of the crystalline domains is greater than $15-20 \AA{ }^{11}$ afterwards when the material becomes much more amorphous the $D$ band changes its form and decreases in intensity. Analyzing the spectra in Fig. 5 it results that the $\mathrm{C}$ film grown with high laser fluences presents an amorphous nature with a mixture of hybridization $s p^{2}$ and $s p^{3} .^{42}$ Decreasing the deposition laser fluence the $\mathrm{C}$ films evolve from an amorphous (mixture of $s p^{2}$ and $s p^{3}$ hybridization) towards a disordered graphite-like structure. This evolution is confirmed by the appearance of a $D$ band $^{42}$ and it is in agreement with the results obtained with the EELS measurements.

We did not observe any difference between the spectra of $\mathrm{CN}_{x}$ films with $0.3 \leqslant \mathrm{~N} / \mathrm{C} \leqslant 0.4$ except for the signal coming from the silicon substrate. This signal increases from the film with $\mathrm{N} / \mathrm{C}=0.3$ to the film with $\mathrm{N} / \mathrm{C}=0.4$. Since the films have the same thickness this means an improved transparency in the sample with a higher content of nitrogen in agreement with the XPS results. The increase of the $D$ peak in the $\mathrm{CN}$ films in comparison with the amorphous $s p^{3}$ rich $\mathrm{C}$ films means that the $\mathrm{CN}_{x}$ films have a less amorphous structure. However, in this case we cannot attribute this behavior to an evolution towards a graphite-like structure because the EELS spectra (Fig. 4) showed that these two types of films have almost the same percentage of $s p^{2}$ sites. In agreement with our results different authors, $7,25,26,33$ show that the $D / G$ peak ratio increases by introducing $\mathrm{N}$ in $\mathrm{CN}_{x}$ films, and Bulir et al. ${ }^{33}$ observed that it saturates at about $\mathrm{N} / \mathrm{C}=0.3$. Other works ${ }^{19}$ show that this ratio is fairly constant with increasing $\mathrm{N}$ content in the films. Figure 6 shows the Raman spectra of two $\mathrm{CN}_{x}$ films in the range 2000-2400 $\mathrm{cm}^{-1}$. At about $2220 \mathrm{~cm}^{-1}$ there is a small peak corresponding to the $\mathrm{C} \equiv \mathrm{N}$ stretching mode. ${ }^{16}$ As it appears from the comparison of the two spectra, the amount of $\mathrm{C} \equiv \mathrm{N}$ bonds is the same for the two samples grown with $I_{L}=5 \mathrm{~J} / \mathrm{cm}^{2}(\mathrm{~N} / \mathrm{C}$ $=0.3)$ and $I_{L}=12 \mathrm{~J} / \mathrm{cm}^{2}(\mathrm{~N} / \mathrm{C}=0.4)$ and this amount seems to be very small. This peak is also a fingerprint that nitrogen is chemically bonded to carbon. 


\section{CONCLUSIONS}

We have studied the structural and electronic properties of diamond-like carbon (DLC) and carbon nitride $\left(\mathrm{CN}_{x}\right)$ thin films deposited by pulsed laser deposition (PLD) with different laser density powers. In particular, the $\mathrm{CN}_{x}$ films were grown by laser ablation of graphite in a nitrogen atmosphere. The N/C ratio of the films can reach the value 0.4.

XPS, EELS, and micro-Raman spectroscopy were used to study the different chemical $\mathrm{C}-\mathrm{C}$ and $\mathrm{C}-\mathrm{N}$ bonds. Primarily this study confirms that in $\mathrm{CN}_{x}$ films carbon and nitrogen atoms form stable chemical bonds instead of simple mixing. More specifically, we have studied quantitatively the C $1 s$ and $\mathrm{N} 1 s$ core levels of DLC and $\mathrm{CN}_{x}$ films and, to draw the conclusions, we have characterized the films also by means of EELS and Raman spectroscopy.

In the $\mathrm{CN}_{x}$ films we found that the content of nitrogen increases with the laser fluence. We showed that the fraction of $\mathrm{N}-s p^{3} \mathrm{C}$ bonded sites increases in the film with a higher percentage of nitrogen $(\mathrm{N} / \mathrm{C}=0.4)$. Finally we observed that, for both the $\mathrm{CN}$ and the DLC films, the fraction of $\mathrm{N}-s p^{3} \mathrm{C}$ or $s p^{3} \mathrm{C}$ sites increases sensibly when the deposition laser fluence increases from 5 to $12 \mathrm{~J} / \mathrm{cm}^{2}$.

\section{ACKNOWLEDGMENTS}

The authors would like to thank the Progetto Ricerca Avanzata CLASS of the INFM. F. Schmithüsen is acknowledged for assistance with XPS measurements. Furthermore, S. Ferrer and M. Sancrotti are acknowledged for fruitful discussions.

${ }^{1}$ S. Neuville and A. Matthews, MRS Bull. 22, 22 (1997).

${ }^{2}$ J. Robertson, Prog. Solid State Chem. 21, 199 (1991).

${ }^{3}$ W. I. Milne, J. Non-Cryst. Solids 198-200, 605 (1996).

${ }^{4}$ S. Neuville, A. Tagliaferro, Y. Bounouh, S. Vallon, R. Etemadi, and J. Perrin, Le Vide, Science, Technique and Applications (CIP, Antibes 95, 1995), Vol. 275, p. 64.

${ }^{5}$ D. F. Shriver, P. W. Atkins, and C. H. Langford, Inorganic Chemistry (Oxford University Press, New York, 1989), p. 337.

${ }^{6}$ A. Y. Liu and M. L. Cohen, Phys. Rev. B 41, 10727 (1990).

${ }^{7}$ T. W. Scharf, R. D. Ott, D. Yang, and J. A. Barnard, J. Appl. Phys. 85, 3142 (1999).

${ }^{8}$ J. C. Angus, Plasma Deposited Thin Films (CRC Press, Boca Raton, FL, 1986), p. 89

${ }^{9}$ D. F. R. Mildner and J. M. Carpenter, J. Non-Cryst. Solids 47, 391 (1982).

${ }^{10}$ D. P. Pappas, K. Saenger, J. Bruley, W. Krakow, J. Cuomo, T. Gu, and R. Collins, J. Appl. Phys. 71, 5675 (1992).

${ }^{11}$ A. Kumar and R. B. Inturi, Mater. Res. Soc. Symp. Proc. 397, 289 (1996).

${ }^{12}$ Y. Lifshitz, in The Physics of Diamond, edited by A. Paoletti and A. Tucciarone (IOS, Amsterdam, 1997), Vol. 135
${ }^{13}$ M. L. De Giorgi et al., Appl. Surf. Sci. 127-129, 481 (1998).

${ }^{14}$ S. Acquaviva, A. P. Caricato, M. L. De Giorgi, A. Luches, and A. Perrone, Appl. Surf. Sci. 109/110, 408 (1997).

${ }^{15}$ Y. F. Lu, Z. M. Ren, W. D. Song, D. S. H. Chan, T. S. Low, K. Gamani, G. Chen, and K. Li, J. Appl. Phys. 84, 2909 (1998).

${ }^{16}$ C. Ronning, H. Feldermann, R. Merk, H. Hofsäss, P. Reinke, and J.-U. Thiele, Phys. Rev. B 58, 2207 (1998).

${ }^{17}$ D. Marton, K. J. Boyd, A. H. Al-Bayati, S. S. Todorov, and J. W. Rabalais, Phys. Rev. Lett. 73, 118 (1994).

${ }^{18}$ F. Rossi, B. Andre, A. van Veen, P. E. Mijnarends, H. Schut, F. Labohm, M. P. Delpancke, H. Dunlop, and E. Anger, Thin Solid Films 253, 85 (1994).

${ }^{19}$ N. Hellgren, M. P. Johansson, E. Broitman, L. Hultman, and J. E. Sundgren, Phys. Rev. B 59, 5162 (1999).

${ }^{20}$ H. Sjöström, S. Stafstrom, M. Bonan, and J.-E. Sundgren, Phys. Rev. Lett. 75, 1336 (1995).

${ }^{21}$ S. E. Rodil, N. A. Morrison, J. Robertson, and W. I. Milne, Phys. Status Solidi A 174, 25 (1999).

${ }^{22}$ S. Souto and F. Alvarez, Appl. Phys. Lett. 70, 1539 (1997).

${ }^{23}$ S. Souto, M. Pickholz, M. C. dos Santos, and F. Alvarez, Phys. Rev. B 57, 2536 (1998).

${ }^{24}$ J. Diaz, G. Paolicelli, S. Ferrer, and F. Comin, Phys. Rev. B 54, 8064 (1996).

${ }^{25}$ S. Bhattacharya, C. Cardinaud, and G. Turban, J. Appl. Phys. 83, 4491 (1998).

${ }^{26}$ S. Bhattacharya, J. Hong, and G. Turban, J. Appl. Phys. 83, 3917 (1998).

${ }^{27}$ A. Mansour and D. Ugolini, Phys. Rev. B 47, 10201 (1993).

${ }^{28}$ U. Gelius, P. F. Heden, J. Hedman, B. J. Lindberg, R. Manne, R. Nordberg, R. Nordling, and K. Siegbahn, Phys. Scr. 2, 70 (1970).

${ }^{29}$ M. Barber, J. A. Connor, M. F. Guest, I. H. Hiller, M. Schwarz, and M. Stacey, J. Chem. Soc., Faraday Trans. 2 69, 551 (1973).

${ }^{30}$ G. Beamson and D. Briggs, High Resolution XPS of Organic Polymers (Wiley, New York, 1992).

${ }^{31}$ F. Weich, J. Widany, and Th. Frauenheim, Phys. Rev. Lett. 78, 3326 (1997); 59, 5162 (1999).

${ }^{32}$ Y. F. Lu, Z. F. He, and Z. M. Ren, J. Appl. Phys. 86, 5417 (1999).

${ }^{33}$ J. Bulir, M. Jelinek, V. Vorlicek, J. Zemek, and V. Perina, Thin Solid Films 292, 318 (1997).

${ }^{34}$ Y. H. Yu, Z. Y. Chen, E. Z. Luo, W. Y. Cheung, S. P. Wong, and I. H. Wilson, J. Appl. Phys. 87, 2874 (2000).

${ }^{35}$ S. Uhlmann, Th. Frauenheim, and Y. Lifshitz, Phys. Rev. Lett. 81, 641 (1998).

${ }^{36}$ Peter Kovarik, E. B. D. Bourdon, and R. H. Prince, Phys. Rev. B 48, 12123 (1993).

${ }^{37}$ J. Fink, Th. Muller-Heinzerling, J. Pfluger, B. Scheerer, B. Dishler, P. Koidl, A. Bubenzer, and R. E. Sah, Phys. Rev. B 30, 4713 (1984).

${ }^{38}$ R. F. Egerton, Electron Energy-Loss Spectroscopy in the Electron Microscope (Plenum, New York, 1986); J. D. Jackson, Classical Electrodynamics (Wiley, New York, 1975).

${ }^{39}$ V. I. Merkulov, D. H. Lowndes, G. E. Jellison, Jr., A. A. Puretzky, and D. B. Geohegan, Appl. Phys. Lett. 73, 2591 (1998).

${ }^{40}$ E. Riedo, J. Chevrier, and F. Comin (unpublished).

${ }^{41}$ J. K. Kaufman, S. Metin, and D. D. Saperstein, Phys. Rev. B 39, 13053 (1989).

${ }^{42}$ J. Robertson, Prog. Solid State Chem. 21, 199 (1991). 